\title{
An integrated approach to antimicrobial stewardship in the hospital setting
}

\author{
Coleman Rotstein MD FRCPC ${ }^{1}$, Suzette Salama BPharm PhD², Lionel Mandell MD FRCPC ${ }^{1}$, Michael Cimino MS RPh ${ }^{3}$
}

$\mathrm{T}$ he use of antimicrobials for the therapy and prevention of infection is pervasive in the North American health care system. Antimicrobials are now the second most commonly used class of drugs in the United States and Canada $(1,2)$. In addition, antimicrobial agents contribute significantly to hospital expenditures and account for $5 \%$ to $20 \%$ of a hospital's global budget (3), while comprising $20 \%$ to $50 \%$ of an institution's drug acquisition budget $(4,5)$. Moreover, between $25 \%$ and $33 \%$ of hospitalized patients are treated with antimicrobial agents $(6,7)$.

With such widespread use, it is understandable that surveys have suggested that antimicrobials are inappropriately or incorrectly used in $22 \%$ to $65 \%$ of patients (6-8). In an era of cost containment, controlling antimicrobial use will reduce hospital expenditures; however, the motivation for controlling antimicrobial use is not restricted to monetary issues. Emerging antimicrobial-resistant organisms have developed from selective pressure applied by the misuse and overuse of antimicrobial agents in the hospital setting $(9,10)$. In addition, adverse drug events due to the use of antimicrobial agents affect patient length of stay, costs and attributable mortality $(11,12)$. Appropriate prescribing of anti-infective agents in the hospital setting improves the quality of clinical care provided to patients (13).

An integrated antimicrobial stewardship program is a multidisciplinary activity that attempts to achieve the aforementioned principles $(14,15)$. The specific goals of antimicrobial stewardship are: to prevent the emergence of antimicrobialresistant organisms, to control costs, to enhance the quality of medical care by improving physician performance, to reduce adverse drug events and to provide continuing medical education to physicians and other health care personnel.

The strategies employed to promote an antimicrobial stewardship program in the hospital setting have included both persuasive and restrictive approaches (Table 1). Persuasive techniques attempt to alter physician prescribing behaviour through educational activities for physicians through either direct interaction with prescribers (eg, conferences or lectures) or indirect advice by means of simple chart entry (16); through peer review with delayed feedback on antimicrobial use (17); through academic detailing $(18,19)$; through drug detailing by pharmaceutical representatives (20); through distribution of an antimicrobial handbook $(21,22)$, through development of clinically-based therapeutic guidelines (23) and through computer-assisted decision support (13). In contrast, restrictive strategies have a direct impact on antimicrobial use patterns by limiting prescribing behaviour. Techniques employed to alter physician prescribing behaviour have included a controlled formulary system (24-26), automatic stop orders (25), automatic therapeutic interchange $(24,27,28)$, antimicrobial order forms (25,29-31), restricted antimicrobial agents (24) and infectious diseases consultations for specific agents. Consultations vary from verbal authorization to employ a particular antimicrobial agent (32), to actual authorization granted

${ }^{1}$ Division of Infectious Diseases and the Department of Medicine, Henderson Site, Hamilton Health Sciences Corporation and McMaster University, Hamilton, Ontario, ${ }^{2}$ Research Office, Hamilton Health Sciences Corporation, Hamilton, Ontario and ${ }^{3}$ Department of Pharmacy, Children's Hospital of Buffalo, Buffalo, New York

Correspondence and reprints: Dr Coleman Rotstein, McMaster Medical Unit, Henderson Site, Hamilton Health Sciences Corporation, 711 Concession Street, Hamilton, Ontario L8V 1C3. Telephone 905-574-3301, fax 905-575-7320, e-mail crotstei@fhs.mcmaster.ca 
TABLE 1

Strategies to improve physician prescribing behaviour

\begin{tabular}{ll}
\hline Persuasive & Restrictive \\
\hline Education for prescribers & Controlled formulary \\
Peer review & Automatic stop orders \\
Academic detailing by pharmacists & Automatic therapeutic interchange \\
Detailing by pharmaceutical & Antimicrobial order forms \\
representatives & Restrictive antimicrobial policies \\
Antimicrobial handbook & Infectious diseases consultations \\
Therapeutic guidelines & \\
Computer-assisted decision & \\
support & \\
\hline
\end{tabular}

with communication to the pharmacy before the release of the agent (33-35), to a mandatory formal written consultation with subsequent advice on antimicrobial management from a infectious diseases physician. The strategy of employing mandatory infectious diseases consultation has been described as a complementary action to concurrent review of antimicrobial therapy by a clinical pharmacist. In this scenario, the clinical pharmacist advises attending physicians on alternative therapy or dose modification, and an infectious diseases consultation is sought only if disagreement occurs (34).

The strategies described above have met with varying degrees of success. The most successful and lasting effects have been accomplished through restrictive prescribing methodologies $(25,29-34)$ or computer-assisted decision support (13). However, concerns have been voiced that restrictive policies might result in suboptimal antimicrobial use or may compromise patient care $(35,36)$. Moreover, Kassirer (37) has advocated that quality improvement policies should not only control antimicrobial use but also be informative.

Unlike restrictive policies, the impact of any facilitative educational intervention is often difficult to assess because of the complex nature of educational variables and because the effects of education often decay over time unless they are continuously reinforced. Furthermore, the diverse nature of educational interventions, the lack of standardized evaluation and the interaction of emotional, philosophical, patient and laboratory parameters that contribute to clinical decisionmaking regarding antimicrobial therapy make assessments and comparisons of these interventions very labour intensive.

The success of an antimicrobial stewardship program depends upon the involvement of individuals dedicated to the program. Hospital personnel who are passionate about the goals of antimicrobial stewardship often gravitate towards such a program. These individuals include representatives from the departments of pharmacy, clinical microbiology, infectious diseases, infection control, nursing and administration, and prescribing physicians. A steering committee to assist in initiating and facilitating the operation of the program should comprise these individuals (15) (Table 2). The committee has a central role in formulating policies and developing the strategies to achieve the goals of the program, and should
TABLE 2

Composition of steering committee for antimicrobial stewardship program

Infectious diseases physician

Pharmacist

Microbiologist

Infection control practitioner

Surgeon

General internist

Intensivist

Paediatrician

Obstetrician and gynecologist

Emergency department representative

Nursing department representative

Administrator

be charged with spearheading action for evaluating antimicrobial use through drug utilization reviews (DUR) as well as cost and outcome analyses. These actions provide the necessary data required to gauge what antimicrobial use problems exist.

Approaches to DURs have been drug-specific (ie, evaluating vancomycin use) (38), directed against antimicrobial agents used in specific clinical syndromes (ie, the treatment of community-acquired pneumonia) or service directed (ie, antimicrobial agents used on the orthopedic service) (4) and may be performed either regularly or sporadically over various time frames. Information collected can be used to create physicianspecific profiles of prescribing patterns. Data on physician prescribing profiles that evaluate the appropriateness of antimicrobial prescribing may be employed administratively in the physician credentialing process. Failure to meet peer-accepted standards of prescribing guidelines may also be grounds for failing to achieve an appropriate standard of care, and, therefore, obstruct reappointment (9). DUR data may also be provided to various other administrative committees such as the Pharmacy and Therapeutics, Quality Assurance or Outcomes Evaluation Committees. Thus, DURs are an excellent example of multidisciplinary activity in the hospital setting involving pharmacy-physician and physician-administration interactions.

An integrated antimicrobial stewardship program was developed and implemented by the authors and evolved over a number of years at the Henderson site of the Hamilton Health Sciences Corporation. This program comprises several components and was implemented through the following strategies: a hospital formulary system, automatic stop orders, therapeutic guidelines, automatic therapeutic interchanges, antimicrobial order forms, antimicrobial restriction policies, mandatory infectious diseases consultations and a sequential antimicrobial therapy program. Each component of the program played an integral role in its ultimate success.

\section{HOSPITAL FORMULARY SYSTEM}

Hospital antimicrobial formularies are restricted prescribing lists of antimicrobial agents that are drawn up using clear criteria. Formularies should be reviewed regularly by qualified staff and should contain products with the best cost to benefit 
TABLE 3

Example of an antimicrobial formulary

\begin{tabular}{cl}
\hline Parenteral Agents & \\
Antibacterial & \\
Penicillin G K & Meropenem* \\
Procaine penicillin G & Centamicin \\
Benzathine penicillin G & Tobramycin* \\
Cloxacillin & Amikacin* \\
Piperacillin & Clindamycin \\
Piperacillin-tazobactam* & Metronidazole \\
Cefazolin & Vancomycin* \\
Cefuroxime & Trimethoprim/ \\
& sulfamethoxazole \\
Cefotetan* & Ciprofloxacin* \\
Cefotaxime* & Doxycycline \\
Ceftazidime* & Erythromycin lactobionate \\
Antifungal & Fluconazole* \\
Amphotericin B & Pentamidine* \\
Amphotericin B lipid & \\
complex* & \\
Antiviral & Ganciclovir \\
Acyclovir & \\
Oral Agents & Vancomycin* \\
Antibacterial & Metronidazole \\
Penicillin Vee & Azithromycin \\
Cloxacillin & Isoniazid \\
Amoxicillin & Rifampin \\
Cephalexin & Rifabutin* \\
Cefuroxime axetil & Pyrazinamide \\
Clindamycin & Ethambutol \\
Doxycycline & \\
Trimethoprim/ & \\
sulfamethoxazole & \\
Ciprofloxacin & Itraconazole* \\
Antifungal & Dapsone* \\
Kystatin & \\
Fluconazonazole & Indinavir \\
Antiviral & Saquinavir \\
Acyclovir & Didanosine* \\
Famciclovir* & \\
Ganciclovir & \\
Zidovudine & Lamuvidine \\
Antiparasitic & Pyramethamine* \\
\hline
\end{tabular}

*Restricted agent requiring Infectious Diseases approval

ratio within their jurisdiction. When employed in the forementioned manner, antimicrobial formularies are cost-saving measures because they streamline the number of agents purchased, delete superfluous agents and thus, minimize cost (39-41). Furthermore, the formulary system has been endorsed by the Society for Healthcare Epidemiology of America and the Infectious Diseases Society of America as a policy that aids in the control of antimicrobial resistance (42). The basic tenets of choosing agents for the formulary are that the agents must be efficacious, have low toxicity profiles, possess pharmacokinetic advantages, have cost advantages compared with drugs of the same class and have a low predilection for the development of resistance. With these principles in mind, Table 3 shows an example of antimicrobial formulary listing.

Multidisciplinary input is required for the selection of agents for the formulary. This cooperative venture involving physicians, pharmacists, infection control practitioners, microbiology representatives and administrators (comprising

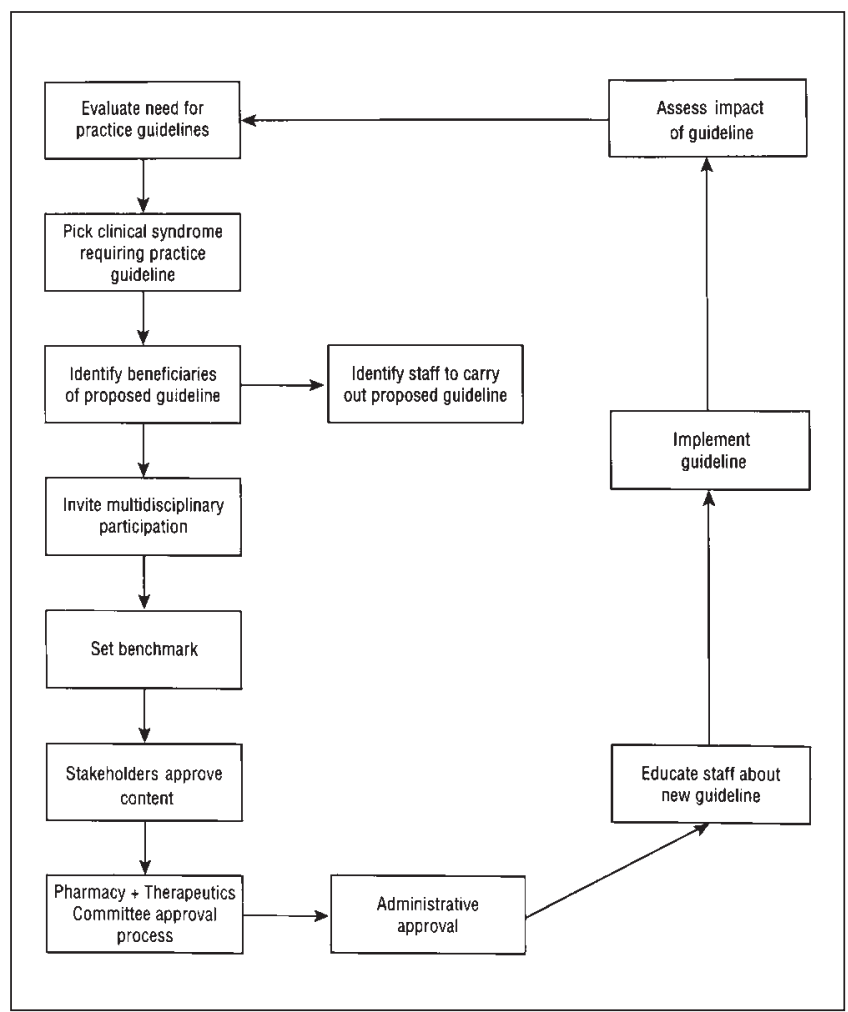

Figure 1) Development of therapeutic practice guidelines

the Antimicrobial Stewardship Steering Committee) should forward recommendations to the Pharmacy and Therapeutics Committee for final administrative approval. Input from microbiology representatives is essential in formulary establishment because routine susceptibility testing is done only for formulary agents. In turn, the microbiology laboratory may employ graded susceptibility reporting with the usual dosing recommendations, renal dose adjustments and costs that streamline clinician antimicrobial choices.

However, considerable debate surrounds the use of formulary systems. Concerns about the perception of the restriction of clinical freedom, the validity of the process of selection and/or restriction and sacrificing patient care to cost control, and the perceived negative impact on pharmaceutical research and development have been voiced (43). However, although the antimicrobial formulary system possesses intrinsic limitations, it is an integral part of the stewardship program that provides a rational approach to prescribing and assisting the control of antimicrobial resistance and costs.

\section{AUTOMATIC STOP ORDERS}

The objective of automatic stop orders is to necessitate reassessment of the need for antimicrobial therapy $(15,42)$. Different schemas have been developed for the implementation of this strategy - some institutions employ automatic stop orders for intravenous agents only, while others apply this strategy to both parenteral and oral agents. Commonly employed stop dates for parenteral agents are three or seven days, while five or seven days are frequently used for oral agents. In par- 


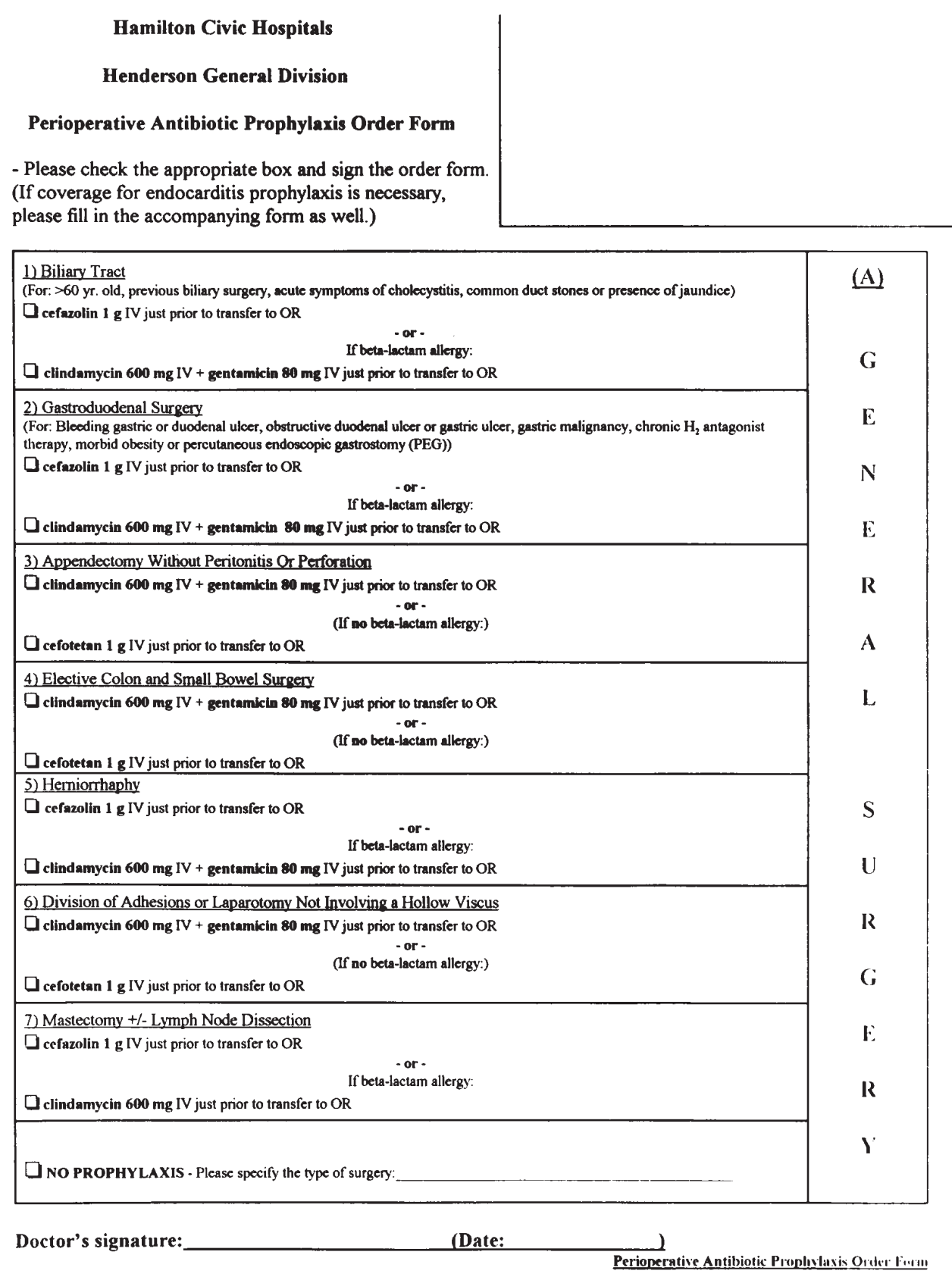

Figure 2) Perioperative antimicrobial prophylaxis order form for general surgery procedures

ticular, this technique may be most successful when applied to surgical perioperative prophylaxis (eg limiting the prescription of drugs to $24 \mathrm{~h}$ postoperation). A caveat to the use of automatic stop orders is that health care facilities must institute precautions that prevent inadvertent lapses in continuous therapy.

This strategy encourages interaction between pharmacists and physician prescribers. Adherence to this strategy must be handled in a professional manner with mutual respect between the professionals involved. In our institution, automatic stop orders at $72 \mathrm{~h}$ for intravenous drugs are enforced by the pharmacy and encourage reassessment of the need for further therapy at this juncture. It is anticipated that additional clinical and laboratory information is available by $72 \mathrm{~h}$ of therapy, enabling physicians to consider other options such as conversion from intravenous to oral therapy (24).

\section{THERAPEUTIC GUIDELINES}

Therapeutic guidelines are a means of facilitating antimicrobial stewardship. Formulation of guidelines should follow the pathway outlined in Figure 1. Initially, the need for the guidelines should be assessed with the recognition of who will benefit and who should set the bench mark for the guidelines. Later, widespread consultation leads to the approval phase 
TABLE 4

Examples of automatic therapeutic substitutions

\begin{tabular}{lc}
\hline Originally prescribed drug & Therapeutic alternative \\
\hline $\begin{array}{l}\text { Ampicillin } 250 \text { to } 500 \mathrm{mg} \text { every } 6 \mathrm{~h} \\
\text { orally }\end{array}$ & $\begin{array}{c}\text { Amoxicillin } 250 \text { to } 500 \mathrm{mg} \\
\text { every } 8 \mathrm{~h} \text { orally }\end{array}$ \\
$\begin{array}{l}\text { Cephalothin } 1 \text { to } 2 \mathrm{~g} \text { every } 4 \mathrm{~h} \\
\text { intravenously }\end{array}$ & $\begin{array}{c}\text { Cefazolin } 1 \text { to } 2 \text { g every } 8 \mathrm{~h} \\
\text { intravenously }\end{array}$ \\
Cefoxitin 1 to $2 \mathrm{~g}$ every $6 \mathrm{~h}$ & Cefotetan $1 \mathrm{~g}$ every $12 \mathrm{~h}$ \\
intravenously & intravenously \\
Cefotaxime $1 \mathrm{~g}$ every $8 \mathrm{~h}$ & Ceftriaxone $1 \mathrm{~g}$ every $24 \mathrm{~h}$ \\
intravenously & intravenously \\
Cefotaxime $2 \mathrm{~g}$ every $4 \mathrm{~h}$ & Ceftriaxone 2 g every $12 \mathrm{~h}$ \\
intravenously & intravenously \\
Vancomycin $125 \mathrm{mg}$ qid orally & Metronidazole $250 \mathrm{mg}$ qid orally \\
Gentamicin $1.5 \mathrm{mg} / \mathrm{kg}$ every $8 \mathrm{~h}$ & Gentamicin 4 to $6 \mathrm{mg} / \mathrm{kg}$ every \\
intravenously & 24 intravenously \\
\hline
\end{tabular}

with subsequent education of the users of the guidelines by way of newsletters, educational rounds, pocket charts, wall posters (24) or computer-assisted decision support (5). It is very important to build a consensus so that participants in the program become committed to adhering to the guidelines. Finally, the impact of the guidelines should also be evaluated.

On occasion, therapeutic guidelines may be combined with another more restrictive antimicrobial stewardship strategy, such as antimicrobial order forms. This method has been employed very successfully by the authors to decrease inappropriate prescribing of perioperative antimicrobial prophylaxis (44). Not only did the perioperative antimicrobial prophylaxis order form promote the appropriate use of antimicrobials for surgical prophylaxis, but it standardized prophylactic regimens, ensured the timely administration of the prophylactic agents, had a long lasting effect and reduced drug acquisition costs. Universal distribution of the form to nursing units, physician offices and the emergency department with continued stakeholder input ensured compliance with the program. An example of our perioperative antimicrobial prophylaxis order form is shown in Figure 2. Other investigators have demonstrated the benefit of computer-assisted decision support in combination with therapeutic guidelines in improving appropriateness of prescribing, reducing adverse drug events and controlling the emergence of resistance (5).

\section{AUTOMATIC THERAPEUTIC SUBSTITUTIONS}

The practice of therapeutic antimicrobial substitutions has become routine in many health care institutions. Therapeutic substitution implies dispensing a drug different in chemical structure from the one originally prescribed. The substitute must be from the same therapeutic antimicrobial class (therapeutic alternative) and have the same pharmacodynamic properties (ex ceftriaxone substituted for cefotaxime) (Table 4).

Therapeutic substitution originates from the need for rational drug therapy within the context of rising costs and is devised and approved by physician prescribers and administrative committees within an institution. Therapeutic substi-

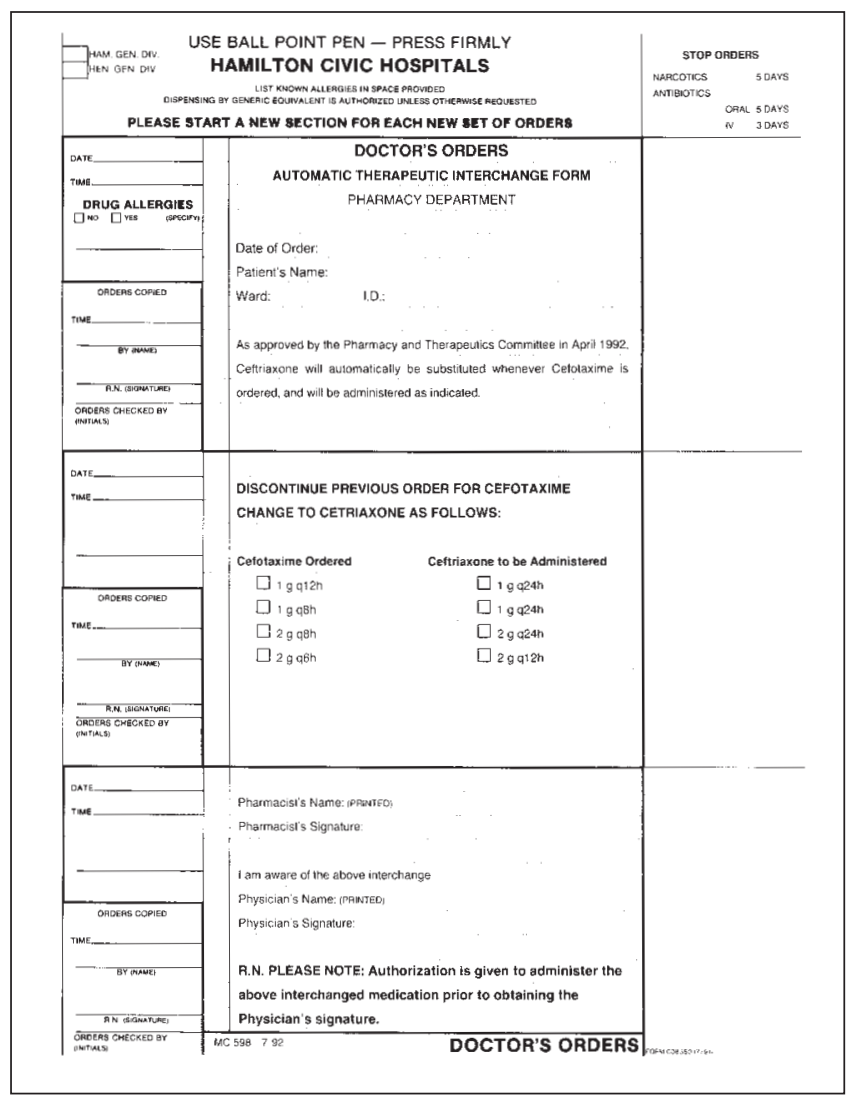

Figure 3) Automatic therapeutic substitution order form

tution implies that the selected substitute will have a comparable therapeutic affect, as compared with the original prescribed agent, although adverse events or potential interactions with the substitute may differ. It has been commonly employed with cephalosporin antibiotics in the literature (45). To safeguard patient welfare, the American College of Physicians has set standards for therapeutic substitution that stipulate that an effectively functioning formulary system and a Pharmacy and Therapeutics Committee must be in place, prescribers must be informed that a substitution has occurred and effective education of physicians in therapeutics should be undertaken (45).

Some therapeutic substitution strategies are agentspecific, similar to those accomplished by Achusim (28), who applied a cefoxitin-to-cefotetan switch and realized cost savings. Other reports have favoured multiple drug switches (24). Furthermore, therapeutic substitution may only involve switching a three-times daily regimen with a once daily regimen, as in the case of once daily aminoglycoside dosing $(46,47)$. The once daily dosing regimens are more economical because they require less time and labour by pharmacy and nursing personnel, but do not sacrifice efficacy.

Certain precautions must be applied to the concept of automatic antimicrobial therapeutic substitution. If the interchange occurs immediately, physician prescribers of the original antimicrobial agent must be alerted to the substitution. This may be carried out by interchange notices placed in the patient's medical record (Figure 3), with subsequent counter- 
TABLE 5

Outcome of 101 consecutive mandatory infectious disease consultations for restricted antimicrobial agents

\begin{tabular}{|c|c|}
\hline $\begin{array}{l}\text { Percentage of patients } \\
(n=101)\end{array}$ & Result of intervention \\
\hline 39 & Intravenous to oral switch \\
\hline 24 & Discontinued all antimicrobial agents \\
\hline 22 & $\begin{array}{l}\text { Discontinued some antimicrobial } \\
\text { agents }\end{array}$ \\
\hline 15 & $\begin{array}{l}\text { Changed to more appropriate } \\
\text { intravenous antimicrobial agents }\end{array}$ \\
\hline
\end{tabular}

signature by the attending physician as acknowledgement of the switch (24). In addition, continued educational efforts must be undertaken by pharmacists and other resource people to apprise physician prescribers of innovations in therapeutic substitution. Adherence to these principles will guarantee the success of this strategy.

\section{ANTIMICROBIAL ORDER FORMS}

The use of antimicrobial order forms, which are often used in combination with other strategies (44), is a significant component of an integrated stewardship program. Order forms permit the collection of data for DURs because they contain written justification of antimicrobial use; however, the quality of the information gathered is dependent on those filling in the forms and, therefore, may be of limited use.

Some institutions use antimicrobial order forms that incorporate questions about the indications for antimicrobial agent use, suggested dosing regimens and duration of therapy. Although this technique is restrictive in nature, it may also have educational value for prescribers. Antimicrobial order forms have been proven to reduce costs (44) and control inappropriate antimicrobial use $(29,30)$.

\section{ANTIMICROBIAL RESTRICTION POLICIES AND INFECTIOUS DISEASES CONSULTATIONS}

Antimicrobial restriction policies have been advocated to curb the spread of antimicrobial-resistant organisms $(9,10,48)$ and inappropriate use of expensive broad-spectrum agents (8), and diminish adverse events (11). These policies are routinely employed in conjunction with some form of approval process or antimicrobial order form $(8,26,49)$. The authors' experience with the restriction of eight antimicrobials associated with the highest acquisition costs (cefotetan, ceftriaxone, ceftazidime, imipenem/cilastatin, vancomycin, tobramycin, amikacin and fluconazole) has been previously reported (24).

Restrictions on antimicrobial use vary among hospitals. Targeted agents requiring justification for their use have included costly, broad-spectrum drugs such as cefotetan, ceftriaxone, ceftazidime, imipenem/cilastatin, aztreonam, ticarcillin/clavulanate, ciprofloxacin and recently more narrowspectrum agents such as vancomycin (50), to which drugresistant organisms have developed. A variety of mechanisms for authorizing the use of these restricted antimicrobials exist. Authorization schemas range from mere verbal approval (32) to written consultation by infectious diseases physicians when restricted agents are employed (34). The former strategy for authorization is predicated upon mutual agreement to seek approval for use from a designated peer by both the prescribing physician and the pharmacy that dispenses the restricted agent. Prescribers are allowed a $24 \mathrm{~h}$ grace period to obtain approval. In a collegial atmosphere, this strategy, which centres on the gate keeper principle, should proceed smoothly; however, adversarial situations may arise if permission is not granted.

A second mechanism of handling restricted agent authorization involves infectious diseases physicians directly. Prescribing physicians are required to contact an infectious diseases physician to obtain consent for the use of a restricted antimicrobial before its administration. In most cases, approval is granted, and the information is conveyed to the pharmacy by the infectious diseases physician; however, an infectious diseases physician must be available on a $24 \mathrm{~h}$ basis, and on occasion, disagreements arise that may jeopardize the infectious diseases physician's role as a clinical consultant. A variation of the approval mechanism involves the use of a preprinted restricted antimicrobial order form with specific indications for the restricted drug that must be completed and signed by the prescriber before the pharmacy can release the drug (24). A $24 \mathrm{~h}$ grace period is allowed for the completion of the form. Failure to comply with the completion of the restricted antimicrobial order form within the grace period triggers notification of the prescriber by the pharmacy. This modification of the first mechanism allows retrospective audits of indications for restricted antimicrobial use and is an excellent quality assurance activity.

The final strategy for controlling the use of restricted antimicrobials is mandatory infectious diseases consultations. This technique has been very successfully employed in the integrated antimicrobial stewardship program at the Henderson site of the Hamilton Health Sciences Corporation. Initially, a restricted antimicrobial order form is completed authorizing dispensing of the restricted agent for $72 \mathrm{~h}$. Subsequently, pharmacy personnel provide notification to infectious diseases physicians of the need for consultation if therapy is to be continued with the restricted agent beyond $72 \mathrm{~h}$. The $72 \mathrm{~h}$ grace period is employed because clinical, microbiological and other laboratory data often become available within this time frame. Moreover, the patient's condition may stabilize within $72 \mathrm{~h}$, creating an opportunity to reassess the need for further therapy with the restricted agent. Other investigators have employed the $72 \mathrm{~h}$ cut-off period to initiate an intervention for restricted agents (51). The outcome of 101 consecutive mandatory consultations for restricted antimicrobials by the auhtors (CR and LM) is shown in Table 5.

Another approach to mandatory infectious diseases consultations relies on collaborative efforts between the clinical pharmacist and the infectious diseases physician. In this scenario, the clinical pharmacist conducts a concurrent review of all orders for restricted antimicrobial agents. Based on the pharmacist's review, recommendations are provided to the prescriber $(52,53)$. Disagreement between the clinical pharmacist and the prescriber automatically result in default to an in- 
TABLE 6

Bioavailability of commonly used oral antimicrobial agents

\begin{tabular}{lc}
\hline Drug & Bioavailability (\%) \\
\hline Penicillin & 60 \\
Amoxicillin & 74 to 92 \\
Ampicillin & 30 to 55 \\
Amoxicillin/clavulanic acid & 60 \\
Cloxacillin & 37 to 60 \\
Cephalexin & 90 to 100 \\
Cefuroxime axetil & 37 to 52 \\
Cefixime & 30 to 50 \\
Azithromycin & 37 \\
Clarithromycin & 55 \\
Erythromycin & 50 \\
Ciprofloxacin & $70-80$ \\
Levofloxacin & $>95$ \\
Metronidazole & $>95$ \\
Clindamycin & 50 \\
Trimethoprim/sulfamethoxazole & 70 to 90 \\
Doxycycline & $>90$ \\
\hline
\end{tabular}

fectious diseases consultation for final adjudication of the need for the restricted agent $(15,36)$.

The restricted antimicrobial policies described above, with or without infectious diseases intervention, have all had varying degrees of success $(29,34,54)$ as assessed by cost reductions and enhanced antimicrobial susceptibilities (32). In the authors' opinion, offering physicians a $72 \mathrm{~h}$ window of antimicrobial use contingent on completing an antimicrobial order form followed by a mandatory consultation ensures compliance with antimicrobial use policies; however, others have very successfully employed computer-assisted decision support to the same end $(5,13)$.

\section{SEQUENTIAL ANTIMICROBIAL THERAPY}

Sequential antimicrobial therapy (SAT) refers to the practice of limiting the use of parenteral antimicrobial agents to the early phases of infection, with the remainder of continuous therapy administered orally. Oral therapy is suited for antimicrobials that have comparable pharmacokinetic and pharmacodynamic properties and bioavailability profiles in both the parenteral and oral forms (55). Oral administration of such agents should be considered an alternative means of therapy, providing that the patient is able to swallow, has a functioning gastrointestinal tract, is clinically stable after improving with initial intravenous therapy and has an infection for which oral therapy is not contraindicated (56). The benefits of SAT include increased patient comfort due to earlier discontinuation of intravenous access devices, thus reducing the risk of nosocomial infection; enhanced mobilization of the patient; earlier discharge from the hospital; improved quality of life; and reduced cost of antimicrobial therapy. Savings are accrued by dispensing with the preparation and administration cost of $\$ 8.20$ per intravenous dose administered (57) and permitting out-of-hospital care.

SAT has been demonstrated to be effective in a number of clinical infections including pneumonia, urinary tract infec-

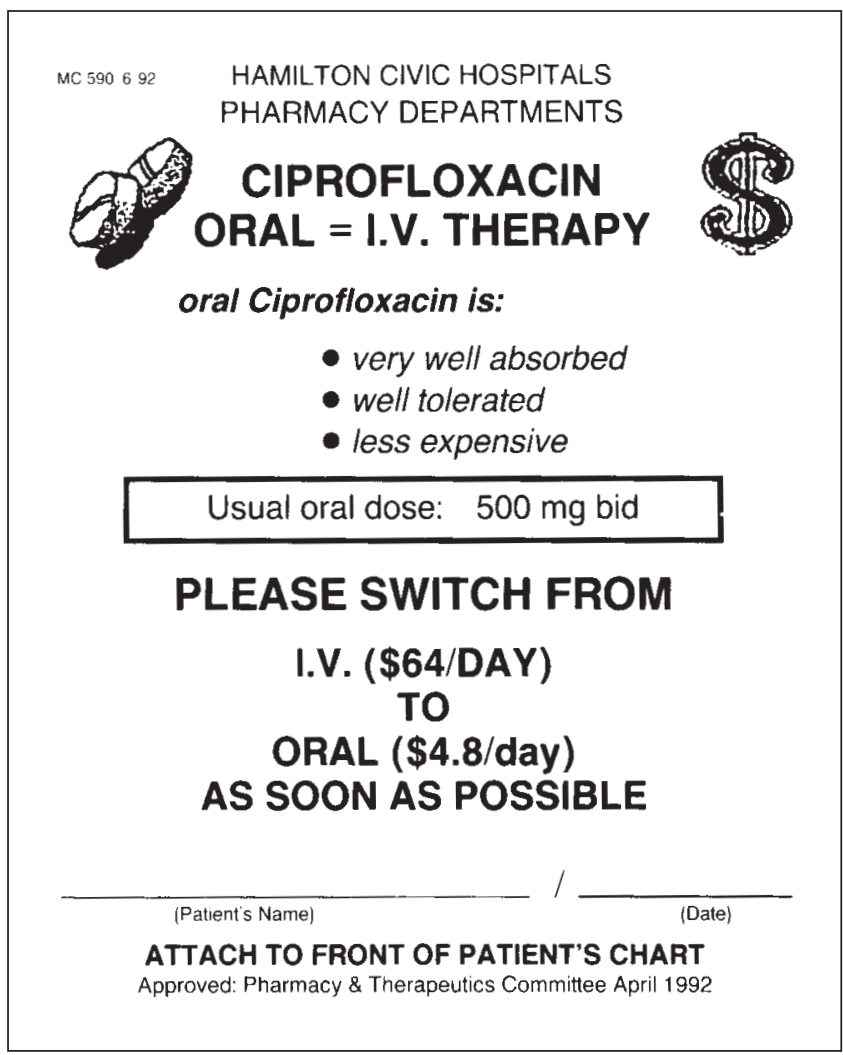

Figure 4) Sequential antimicrobial therapy reminder sticker

tions, intra-abdominal infections, osteomyelitis, septicemia and endocarditis $(55,58,59)$. Nevertheless, therapeutic failure or relapse may occur if poor compliance with oral treatment occurs.

The implementation of SAT may follow syndromic or drugspecific approaches. In the former approach, SAT is promoted for infections such as community-acquired pneumonia, while the latter approach targets a specific drug (eg, metronidazole or ciprofloxacin) (Table 6). In the authors' practice of this strategy, whenever one of a selected group of drugs was ordered for parenteral use, a yellow sticker giving cost and dosage details of the oral formulation was affixed to the patient's medical record as a reminder to the physician that oral treatment should be considered (Figure 4) (24). To attain the maximum impact of this program, constant monitoring was necessary (24). Targeting a specific clinical syndrome may be labour intensive, but has accomplished the anticipated results and reduced costs without sacrificing efficacy (60).

\section{EVALUATION OF ANTIMICROBIAL STEWARDSHIP PROGRAMS}

Due to funding cutbacks in the Canadian health care system, health care facilities have been forced to implement changes in antimicrobial use policies. Health care workers are faced with the challenge of maintaining professional standards while using fewer resources. In the past, the goal of most antimicrobial use policies initially was cost reduction. 
However, with the emergence of multiply resistant organisms and an appreciation for improving patient care outcomes, the aims of antimicrobial stewardship have broadened. Correspondingly, the evaluation of antimicrobial stewardship programs has also evolved.

Measurement tools used to assess the success of antimicrobial stewardship programs have usually evaluated this success in terms of cost savings or cost avoidance (8). John and Fishman (8) have estimated annual cost savings with or without cost avoidance ranging from $\$ 7,440$ to $\$ 483,032$. At the Henderson site of the Hamilton Health Sciences Corporation, a multidisciplinary antimicrobial use program realized annual savings of $\$ 331,080$ and a reduction in the mean cost per dose per patient day from $\$ 11.88$ to $\$ 10.16$. Early SAT has also facilitated a reduction in length of hospital stay, effectively diminishing acute health care facility expenditures (60); however, mere cost savings are insufficient in today's health care environment.

Other measurement modalities have been employed. Controlling antimicrobial-resistant organisms has been used as an end-point for evaluating antimicrobial stewardship programs. Quale and colleagues (61) describe a significant decline in widespread colonization with vancomycin-resistant enterococci by manipulating a hospital antibiotic formulary and altering physician prescribing habits. Others have documented a reduction in nosocomial infection marker events (enterococcal and selected Gram-negative bacteria bloodstream infections; colonization with methicillin-resistant Staphylococcus aureus, Acinetobacter or Stenotrophomonas; and Clostridium difficile-associated diarrhea) with the implementation of an antimicrobial-prescribing improvement program (62). In addition, a nosocomial epidemic of $C$ difficile diarrhea was controlled through the restriction of clindamycin (63). Furthermore, an assessment of antimicrobial resistance has also been used to evaluate the antimicrobial management strategy of cycling or rotating agents - a strategy that has been inadequately explored (64). Although it is widely believed that selective pressure exerted by widespread antimicrobial use is considered to be causally associated with the emergence of resistance, the evidence to support the corollary that 'good antimicrobial control' will prevent the emergence of resistance is only suggestive (42).

Finally, measurement tools for enhancing the quality of medical care are assuming more importance in assessing outcomes of antimicrobial stewardship programs. Pestotnik and coworkers $(5,13)$ used computer-assisted decision support to improve the timing and duration of antimicrobial perioperative prophylaxis while simultaneously decreasing antibioticassociated adverse events by $30 \%$. Similarly, two of the authors (CR and SS) employed a perioperative antimicrobial order form to improve the appropriateness and timing of prophylactic regimens (44). The evaluation of outcomes based on quality of care measurements are preferred to ensure future improvements in patient care. Such evaluations are also in keeping with the recommendations of the Canada Communicable Disease Report on controlling antimicrobial resistance (65).

\section{POTENTIAL OBSTACLES TO THE SUCCESS OF AN INTEGRATED ANTIMICROBIAL STEWARDSHIP PROGRAM IN THE HOSPITAL SETTING}

Any multifaceted program designed to reduce costs, prevent the development of antimicrobial resistance, improve the quality of patient care, reduce adverse events and provide educational benefits to physicians may prove difficult to implement, evaluate and analyze as infectious diseases problems cross all specialty boundaries. Although one may concede that it is an insurmountable task, the ideals of an integrated antimicrobial stewardship program are worth pursuing. In the pursuit of these goals, there are a number of common obstacles that may arise and must be overcome. These roadblocks, reviewed in detail by Goldmann and colleagues (9), include the concepts of lack of ownership of the program and accountability, deficiencies in enforcing the program including the lack of financial support, lack of trust in the hospital administration, lack of local expertise to run the program (ie infectious diseases physicians, clinical pharmacists and electronic information support systems), and lack of evaluation feedback to physicians about the program. Health care facilities must provide the necessary financial resources, personnel and administrative backup to prevent and overcome these obstacles. Failure of a stewardship program may be predicated upon the lack of support personnel to educate, implement and evaluate a program. This may have stemmed from the lack of financial commitment by the institution and may promote lack of trust in the administration, causing physician alienation and resulting in the failure of physicians to alter their prescribing behaviours. A stewardship program requires administration support and physicians must perceive that they have ownership in the program. Finally, in response to poor physician compliance with the program administrators may be prompted to link physician credentialling or reappointment to compliance with the program. Compliance with the program would obviate the need to exercise control over the credentialling process.

In conclusion, integrated antimicrobial stewardship programs in the hospital setting are based on the ideals of promoting better quality patient care, reducing antimicrobial resistance and curtailing hospital expenditures. Such programs hold promise for the future as measures to prevent the emergence of infections that are resistant to all available antimicrobial agents (66). In addition, with the use of antimicrobial stewardship programs physicians will ultimately be successful in achieving improvements in patient management and outcomes.

\section{REFERENCES}

1. American Society for Microbiology. Report of the ASM Task Force on Antimicrobial Resistance. Antimicrob Agents Chemother 1995;39(Suppl):1-23.

2. Therriault I. Rx review. Pharmacy Practice 1994; December:29-36.

3. Ryan BA. The rising cost of pharmaceuticals: an industry observer's perspective. Am J Hosp Pharm 1993;50(Suppl 4):S3-4.

4. Kunin CM. Evaluation of antibiotic usage: a comprehensive look at alternative approaches. Rev Infect Dis 1981;3:745-53.

5. Pestotnik SL, Classen DC, Evans RS, Burke JP. Implementing 
antibiotic practice guidelines through computer-assisted decision support: clinical and financial outcomes. Ann Intern Med 1996;124:884-90.

6. Pelletier LL Jr. Hospital usage of parenteral antimicrobial agents: a gradated utilization review and cost containment program. Infect Control 1985;6:226-30.

7. Dunagan WC, Woodward RS, Medoff G, et al. Antimicrobial misuse in patients with positive blood cultures. Am J Med 1989;87:253-9.

8. John JF Jr, Fishman NO. Programmatic role of the infectious diseases physician in controlling antimicrobial costs in the hospital. Clin Infect Dis 1997;24:471-85.

9. Goldmann DA, Weinstein RA, Wenzel RP, et al. Strategies to prevent and control the emergence and spread of antimicrobial-resistant organisms in hospitals. A challenge to hospital leadership. JAMA 1996;275:234-40.

10. Cohen ML. Epidemiology of drug resistance: implications for a post-antimicrobial era. Science 1992;257:1050-5.

11. Classen DC, Pestotnik SL, Evans RS, Lloyd JF, Burke JP. Adverse drug events in hospitalized patients: excess length of stay, extra costs, and attributable mortality. JAMA 1997;277:301-6.

12. Bates DW, Spell N, Cullin DJ, et al. The costs of adverse drug events in hospitalized patients. JAMA 1997;277:307-11.

13. Evans RS, Pestotnik SL, Classen DC, et al. A computer-assisted management program for antibiotics and other antiinfective agents. N Engl J Med 1998;338:232-8.

14. Conly J, Shafran S. Antimicrobial stewardship. Can J Infect Dis 1997;8:315-6.

15. Duncan RA. Controlling use of antimicrobial agents. Infect Control Hosp Epidemiol 1997;18:260-6.

16. Jones SR, Bark J, Bratten T, et al. The effect of an educational program upon hospital antibiotic use. Am J Med Sci 1977;273:79-85

17. DeSilva MI, Mize GN, Rissing JP. Peer review of antibiotic use: Positive impact on physician prescribing patterns. QRB 1985; 10:302-5.

18. Avorn J, Soumerai SB. Improving drug therapy decisions through educational outreach. A randomized controlled trial of academically based "detailing”. N Engl J Med 1983;308:1457-63.

19. Schentag JJ, Ballow $\mathrm{CH}$, Fritz AL, et al. Changes in antimicrobial agent usage resulting from interactions among clinical pharmacy, the Infection Disease Division and the Microbiology Laboratory. Diagn Microbiol Infect Dis 1993;16:255-64.

20. Plumridge RJ. Review of factors influencing drug prescribing I. Austral J Hosp Pharm 1982;13:16-9.

21. D'Eramo JE, Dupont HL, Preston GA, et al. The short and long term effects of a handbook on antimicrobial prescribing patterns of hospital physicians. Infect Control 1983;4:209-14.

22. Girotti MJ, Fodoruk S, Irvine-Meek J, Rotstein OD. Antibiotic handbook and preprinted perioperative order forms for surgical prophylaxis: do they work? Can J Surg 1990;33:385-8.

23. Gould IM, Hampson J, Taylor EW, Wood MJ. Working party report: Hospital antibiotic control measures in the UK. J Antimicrob Chemother 1994;34:21-42.

24. Salama SE, Rotstein C, Mandell L. A multidisciplinary hospital-based antimicrobial use program: Impact on hospital pharmacy expenditures and drug use. Can J Infect Dis 1996; 7:104-9.

25. Marr JJ, Moffet HL, Kunin CM. Guidelines for improving the use of antimicrobial agents in hospitals: a statement by the Infectious Diseases Society of America. J Infect Dis 1988;157:869-76.

26. Woodward RS, Medoff G, Smith MD, Gray JL. Antibiotic cost savings from formulary restrictions and physician monitoring in a medical school-affiliated hospital. Am J Med 1987;83:817-23.

27. Frighetto L, Nickoloff D, Jewesson P. Antibiotic therapeutic interchange: Six years of experience. Hosp Formul 1995;30:92-105.

28. Achusim LE. Antibiotic use following implementation of a therapeutic interchange program. Pharmacol Ther 1992; 17:775-98.

29. Echols RM, Kowalsky SF. The use of an antibiotic order form for antibiotic utilization review: Influence on physicians' prescribing patterns. J Infect Dis 1984;150:803-7.
30. Avorn J, Soumerai SB, Taylor W, Wessels MR, Janousek J, Seiner $M$. Reduction of incorrect antibiotic dosing through a structured educational order form. Arch Intern Med 1988;148:1720-4.

31. Soumerai SB, Avorn J, Taylor WC, Wessels M, Maher D, Hawley SL. Improving choices of prescribed antibiotics through concurrent reminders in an educational order form. Med Care 1993;31:552-8.

32. White AC Jr, Atmar RL, Wilson J, Cate TR, Stager CE, Greenberg $\mathrm{SB}$. Effects of requiring prior authorization for selected antimicrobials: Expenditures, susceptibilities, and clinical outcomes. Clin Infect Dis 1997;25:230-9.

33. Himmelberg CJ, Pleasants RA, Weber DJ, et al. Use of antimicrobial drugs in adults before and after removal of a restriction policy. Am J Hosp Pharm 1991;48:1220-7.

34. Abel SR, Guba EA. Evaluation of an imipenem/cilastatin target drug program. DICP 1991;25:348-50.

35. Dunagan WC, Medoff G. Formulary control of antimicrobial usage. What price freedom? Diag Microbiol Infect Dis 1992;16:265-74.

36. Bryan CS. Strategies to improve antibiotic use. Infect Dis Clin North Am 1989;3:723-34.

37. Kassirer JP. The quality of care and the quality of measuring it. N Engl J Med 1993;329:1263-5.

38. Singer MV, Haft R, Barlam T, Aronson M, Shafer A, Sands KE. Vancomycin control measures at a tertiary-care hospital: Impact of interventions on volume and patterns of use. Infect Control Hosp Epidemiol 1998;19:248-53.

39. American Society of Hospital Pharmacists. ASHP technical assistance bulletin on hospital formularies. Am J Hosp Pharm 1985;42:375-7.

40. American Society of Hospital Pharmacists. ASHP technical assistance bulletin on the evaluation of drugs for formularies. Am J Hosp Pharm 1988;45:386-7.

41. Green JA. Point: The formulary system and the emperor's new clothes. Am J Hosp Pharm 1986;43:2830-4.

42. Shlaes DM, Gerding DN, John JF Jr, et al. Society for Healthcare Epidemiology of America and Infectious Diseases Society of America Joint Committee on the Prevention of Antimicrobial Resistance: Guidelines for the prevention of antimicrobial resistance in hospitals. Infect Control Hosp Epidemiol 1997; 18:275-91.

43. Rucker TD, Schiff G. Drug formularies: Myths in formation. Med Care 1990;28:928-42.

44. Au P, Salama S, Rotstein C. Implementation and evaluation of a preprinted perioperative antimicrobial prophylaxis order form in a teaching hospital. Can J Infect Dis 1998;9:157-66.

45. Hoover SE, White LJ, Weiner J. Therapeutic substitution and formulary systems. Ann Intern Med 1990;113:160-3.

46. Gilbert DN. Once daily aminoglycoside therapy. Antimicrob Agents Chemother 1991;35:399-405.

47. Hatala R, Dinh T, Cook DJ. Once-daily aminoglycoside dosing in immunocompetent adults: A meta-analysis. Ann Intern Med 1996; 124:717-25

48. Hospital Infection Control Practices Advisory Committee (HICPAC). Recommendations for preventing the spread of vancomycin resistance. Infect Control Hosp Epidemiol 1995; 16:105-13.

49. Maswoswe JJ, Okpara AU. Enforcing a policy for restricting antimicrobial drug use. Am J Health System Pharm 1995;52:1433-5.

50. Anglim AM, Klym B, Byers KE, Scheld WM. Farr BM. Effect of a vancomycin restriction policy on ordering practices during an outbreak of vancomycin resistant Enterococcus faecium. Arch Intern Med 1997;157:1132-6.

51. Fraser G, Stogsdill P, Dickens Jr. JD, Wennberg DE, Smith RP Jr, Prato S. Antibiotic optimization: An evaluation of patient safety and economic outcomes. Arch Intern Med 1997;157:1689-94.

52. Jozefiak ET, Lewicki JE, Kozinn WP. Computer-assisted antimicrobial surveillance in a community teaching hospital. Am J Health-Syst Pharm 1995;52:1536-40.

53. Coleman RW, Rodondi LC, Kaubisch S, Granzella NB, O'Hanley PD. Cost-effectiveness of prospective and continuous parenteral antibiotic control: Experience at the Palo Alto Veterans Affairs Medical Center from 1987 to 1989. Am J Med 1991;90:439-44.

54. Devito JM, John Jr. JF. Effect of formulary restriction of cefotaxime usage. Arch Intern Med 1985;145:1053-6. 
55. MacGregor RR, Graziani AL. Oral administration of antibiotics: A rational alternative to the parenteral route. Clin Infect Dis 1997;24:457-67.

56. Quintiliani R, Nightingale CH, Crowe HM, Cooper BW, Bartlett $\mathrm{RC}$, Gousse G. Strategic antibiotic decision-making at the formulary level. Rev Infect Dis 1991;13(Suppl 9):S770-7.

57. Mithani H, Brown G. The economic impact of once-daily versus conventional administration of gentamicin and tobramycin. Pharmacoeconomics 1996;10:494-503.

58. Parker RJ, Fossieck BE Jr. Intravenous followed by oral antimicrobial therapy for staphylococcal endocarditis. Ann Intern Med 1980;93:832-4.

59. Mandell LA, Bergeron MG, Gribble MJ, et al. Sequential antibiotic therapy: Effective cost management and patient care. Can J Infect Dis 1995;6:306-15

60. Ramirez JA, Srinath L, Ahkee S, Huang A, Raff MJ. Early switch from intravenous to oral cephalosporins in the treatment of hospitalized patients with community acquired pneumonia. Arch Intern Med 1995;155:1273-6.

61. Quale J, Landman D, Saurina G, Atwood E, DiTore V, Patel K.
Manipulation of a hospital antimicrobial formulary to control an outbreak of vancomycin-resistant enterococci. Clin Infect Dis 1996;23:1020-5.

62. Frank MO, Batteiger BE, Sorenson SJ, et al. Decrease in expenditures and selected nosocomial infections following implementation of an antimicrobial-prescribing improvement program. Clin Perform Quality Health Care 1992;5:180-8.

63. Pear SM, Williamson TH, Bettin KM, Gerding DN, Galgiani JN. Decrease in nosocomial Clostridium difficile-associated diarrhea by restricting clindamycin use. Ann Intern Med 1994;120:272-7.

64. Gerding DN, Larson TA, Hughes RA, Weiler M, Shanholtzer C, Peterson LR. Aminoglycoside resistance and aminoglycoside usage: Ten years experience in one hospital. Antimicrob Agents Chemother 1991;35:1284-90.

65. Anon. Controlling antimicrobial resistance: An integrated action plan for Canadians. Can Commun Dis Rep 1997;(Suppl)23S7:1-32.

66. Cohen ML. Epidemiology of drug resistance. Science 1992;257:1050-5. 


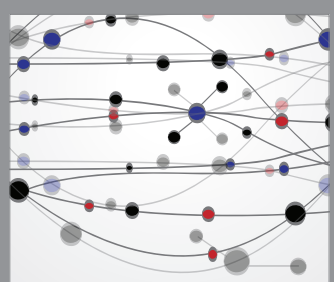

The Scientific World Journal
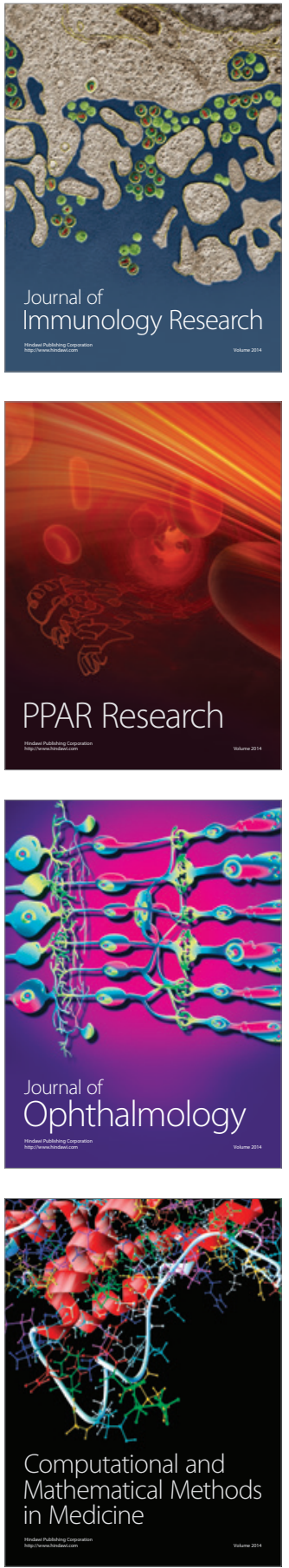

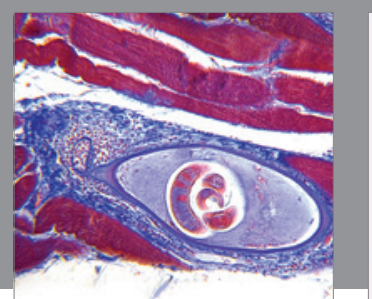

Gastroenterology Research and Practice

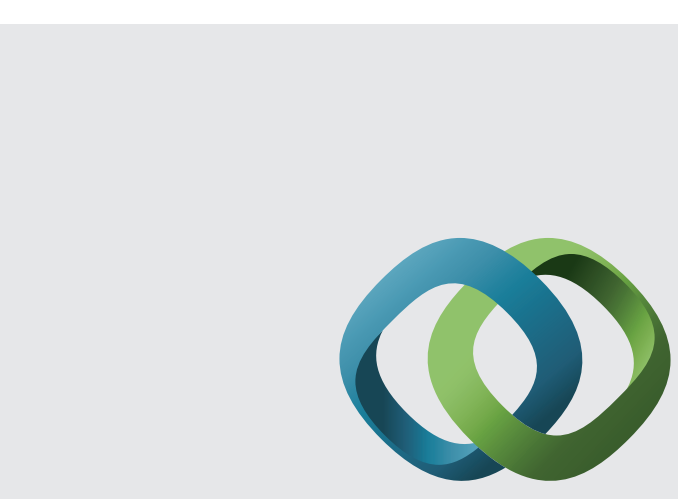

\section{Hindawi}

Submit your manuscripts at

http://www.hindawi.com
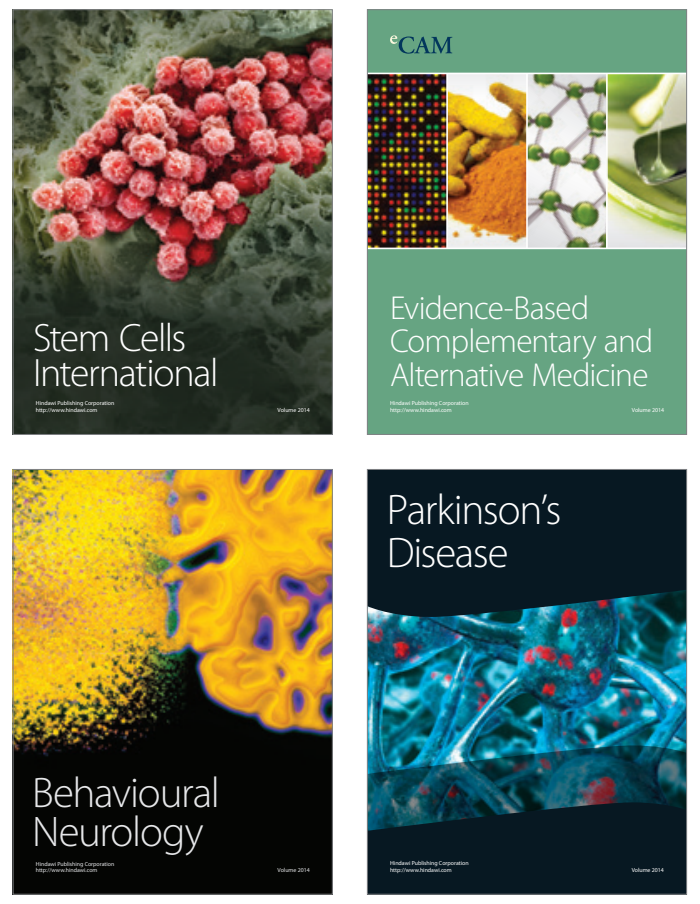
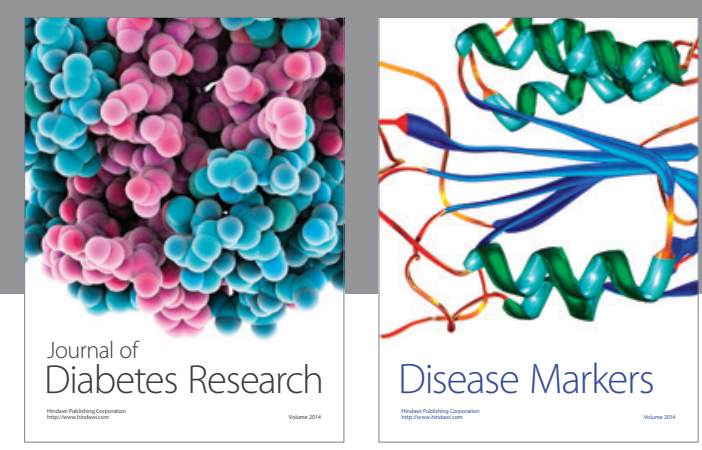

Disease Markers
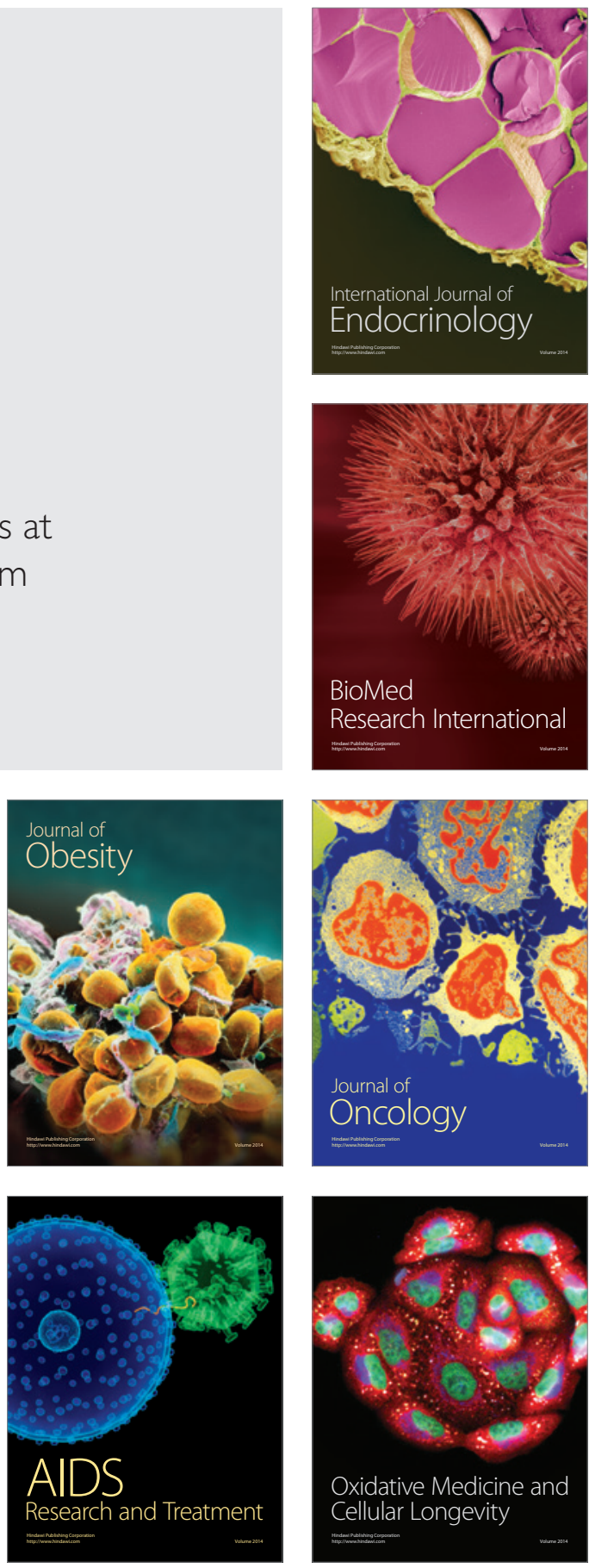